\title{
Parasitic Diseases of Indigenous Community (Kumal) in Nepal
}

\author{
P. Gyawali \\ CSIRO Land and Water, EcoScience Precinct \\ 41 Boggo Road, Dutton Park \\ QLD 4102, Australia \\ e-mail:Pradip.gyawali@uqconnect.edu.au
}

\begin{abstract}
Parasitic infection is common in indigenous community in low land of Nepal. Their life expectancy is well below in comparison to the other people. Kumal are disadvantaged group of people with low socio-economic condition. This study investigated helminthic infection in Kumal community in Gaidakot VDC, Chitwan district people. In this study $17 \%$ of total population of Kumal was selected and helminth parasitic eggs and larvae were detected by floatation method. Half of the study population had at least one helminthic parasite in their body. Hookworm was the most common parasites with $30.87 \%$ followed by Ascaris, Hymenolepsis, Trichuris, Strongyloide and Taenia with $16.10 \%, 6.04 \%, 3.35 \%, 2.68 \%$ and $2.01 \%$ respectively. Fourty years and older population were highly affected by helminths in both sexes. Single, double and multiple parasitic eggs also were recorded in the study population.
\end{abstract}

\section{Introduction}

Parasitic helminths of humans are major public health problems around the world. This is particularly in developing and under developed countries where transmission of geohelminth is accelerated by poor sanitation and hygiene (WHO 2004, Gordon et al. 2011). Other global phenomenan such as climate change, migration, environmental changes, drug resistance and economic factors make things more complicated into the public health (Thompson \& Conlan 2011). It is estimated that soil transmitted helminthes have affected more than two billion people worldwide (WHO 2004). Nearly one billion of world population are infected with roundworm, followed by 800 million with whipworm and 700 million with hookworms (Brooker et al. 2004). Poverty is the main cause of helminth infections. This situation leads to poor nutrition, inadequate sanitation and lack of appropriate health care and clean water. Helminth infections can cause a range of serious health complications and chronic infections can lead to the hosts' death (WHO, UNICEF 2004, Friedman et al. 2005, Bethony et al. 2006, Liang \& Spear 2008).
Kumal is one of the major tribe communities in lowland Nepal, who is heavily dependent on natural resources for its livelihood. They are more likely to get geohelminths than other counterparts in Nepal due to their occupation and dependency in nature. They have limited excess to the health service, education and safe drinking water due to the higher cost of those services in Nepal (Upreti \& Adhikari 2006). The health care practices of these communities rely on traditional healers known as Dhami and Jhakri who perform ancient rites of protection, blessing and healing (Chaudhary 2001). There was not any literature that suggests traditional healing can stop infection of worms.

There have been few studies conducted in other indigenous communities in different parts of Nepal (Sharma 1965, Kharel 2000, Biggs \& Wathmough 2012). However, there has not been any study carried out in situations of helminthes parasites in this tribe. In this study we propose to investigate the helminth infections in this particular community. 


\section{Methodology}

\section{Study area}

This study was conducted in Gaindakot Village Development Committee (VDC), Chitwan. All the samples of the worms were collected in rainy season. According to the VDC, the total population of Kumal was about 800 persons in 124 households. The Kumal people are found to be distributed in the bank of river and edge of the jungle around the VDC. Most of the people of this community are illiterate groups in this VDC. Farming, fishing, and labour are major livelihood activities for these communities.

\section{Sample collection}

A total of 149 faecal samples were collected from 77 females and 72 males of age 5 to 80 years old. For the collection of sample, a clean, dry, screw capped and properly labelled plastic container was distributed to all individual and samples were collected following morning.

\section{Laboratory method}

Faecal specimens were preserved with 5\% formaline and carried to the laboratory of central Department of Zoology, Kirtipur, Nepal. Magnesium floating method described by Deyden et al. (2006) was applied to recover the parasitic eggs from the faecal samples because only helminthic infection was studied. Approximately $2 \mathrm{~g}$ of faecal sample was weighed. $10 \mathrm{ml}$ of magnesium sulphate solution was measured with a pipette and added in the $2 \mathrm{~g}$ of sample. The mixture was blended completely and poured into a $10 \mathrm{ml}$ test tube by filtering with the help of a strainer. A coverslip was placed on top of the test tube and left for approximately ten minutes to collect floating eggs and worms of helminths. The coverslip was taken from the test tube with some liquid on its surface and placed on a glass slide. The prepared slide was observed under 40x of Olympus microscope. Observation was started one end of the slide to another end. The objects were focused under the high power 100x for detailed diagnosis. While examining, precaution was taken to ensure the films do not get dried. The findings were analysed statistically by using Chi square test.

\section{Results and Dissucssion}

The overall prevalence of parasitic helminths in Kumal people was found to be $48.99 \%$ (73/149), in which $45.83 \%$ (33/72) were males and $51.94 \%(40 / 77)$ were females as shown in Table 1. In male, the highest prevalence rate $(80 \%)$ was found in the age group of $40+$ years whereas the lowest prevalence rate $(21.4 \%)$ was found in the age group of 21-30 years. Similarly, in female population highest prevalence $(75.0 \%)$ was recorded in the $40+$ years but conversely lowest infection rate $(36 \%)$ was found in the age group of less than 10 years. However, in overall population the highest prevalence rate $(76.9 \%)$ was found in 40+years and lowest prevalence rate $(36.7 \%)$ was found in below 10 years as shown in Table 1. In both sexes older people were found to be infected by helminth parasites but the result was not found to be statistically significant.

Table 1. Age and sexwise prevalence of helminth parasites in the study population

\begin{tabular}{l|l|l|l|l|l|l|l|l|l}
\hline $\begin{array}{l}\text { Age } \\
\text { group } \\
\text { (yrs) }\end{array}$ & $\begin{array}{l}\text { Male } \\
\text { sample } \\
(\mathrm{n})\end{array}$ & $\begin{array}{l}+\mathrm{ve} \\
(\mathrm{n})\end{array}$ & $\begin{array}{l}+\mathrm{ve} \\
(\%)\end{array}$ & $\begin{array}{l}\text { Female } \\
\text { Sample } \\
(\mathrm{n})\end{array}$ & $\begin{array}{l}+\mathrm{ve} \\
(\mathrm{n})\end{array}$ & $\begin{array}{l}+\mathrm{ve} \\
(\%)\end{array}$ & $\begin{array}{l}\text { Total } \\
\text { sample } \\
(\mathrm{n})\end{array}$ & $\begin{array}{l}+\mathrm{ve} \\
(\mathrm{n})\end{array}$ & $\begin{array}{l}+\mathrm{ve} \\
(\%)\end{array}$ \\
\hline$\leq 10$ & 24 & 9 & 37.5 & 25 & 9 & 36.0 & 49 & 18 & 36.7 \\
$11-20$ & 18 & 10 & 55.5 & 16 & 8 & 50.0 & 34 & 18 & 52.9 \\
$21-30$ & 14 & 3 & 21.4 & 20 & 13 & 65.0 & 34 & 16 & 47.0 \\
$31-40$ & 11 & 7 & 63.6 & 8 & 4 & 50.0 & 19 & 11 & 57.8 \\
$>40$ & 5 & 4 & 80.0 & 8 & 6 & 75.0 & 13 & 10 & 76.9 \\
\hline Total & 72 & 33 & 45.8 & 77 & 40 & 51.9 & 149 & 73 & 48.9 \\
\hline
\end{tabular}

The results were not statistically significant at á $=0.05$ level

Hookworm was the most dominant parasite found in the study population followed by Ascaris, Hymenolepsis, Taenia, Strongyloide, and Trichuris also was found in small magnitude. Overall, $30.87 \%$ population had hookworm in their samples followed by $16.10 \%$ Ascaris, 6.04\% Hymenolepsis, 3.35\% Trichuris, $2.68 \%$ Strongyloide and 2.01\% Taenia as shown in Table 2. Sexwise, $20.83 \%$ male and $40.25 \%$ female were infected by hookworm followed by $15.27 \%$ male and $16.88 \%$ female, $8.33 \%$ male and $3.89 \%$ female, $2.77 \%$ male and $3.89 \%$ female were infected by Ascaris, Hymenolepsis and Trichuris respectively. Only male population were affected by Strongyloide and Taenia of 5.55\% and $4.16 \%$ respectively. However, the result was not found to be a statistically significant. 
P. Gyawali/Parasitic Diseases of Indigenous..

Table 2. Prevalence of individual helminth infection in study population

\begin{tabular}{l|c|c|c|c}
\hline Parasites & +ve male $(\mathrm{n})$ & $\%$ & +ve female $(\mathrm{n})$ & $\%$ \\
\hline Hookworm & $15^{*}$ & 20.8 & $31^{*}$ & $13^{*}$ \\
Ascaris & $11^{*}$ & 15.2 & $3^{*}$ & 16.8 \\
Hymenolepsis & $6^{*}$ & 8.3 & $3 *$ & 3.9 \\
Trichuris & $2 *$ & 5.7 & 0 & 3.9 \\
Strongyloide & $4^{*}$ & 4.2 & 0 & 0.0 \\
Taenia & 3 & 4.2 & 0.0 \\
\hline
\end{tabular}

*Parasites also included from mixed infection

The study population showed single, double and triple infections. In which 38.92\% (58/149) were single infection, $8.05 \%(12 / 149)$ were double infection and

$2.01 \%(3 / 149)$ were triple infection. More female population had double infection but more male had triple infection as shown in Table 3.

Table 3. Intestinal infection pattern in the study population (Age 5-80 years)

\begin{tabular}{l|c|l|c|l|c|c}
\hline Infection pattern & +ve male $(\mathrm{n})$ & $\%$ & +ve female $(\mathrm{n})$ & $\%$ & Total $(\mathrm{n})$ & $\%$ \\
\hline Single & 27 & 37.5 & 31 & 40.2 & 58 & 38.9 \\
Double & 4 & 5.5 & 8 & 10.3 & 12 & 8.0 \\
Triple & 2 & 2.7 & 1 & 1.2 & 3 & 2.0 \\
\hline
\end{tabular}

The results were not statistically significant at á $=0.05$ level

Intestinal parasites are cosmopolitan in distribution and causing serious health problem in the society where poverty, illiteracy and use of traditional way of treatment make this indigenous population more vulnerable to the helminth infection (Thompson et al. 2001). Very few of the study population had permanent or temporary toilet. These people used open field for nightsoil disposed. Furthermore, these people used pond and river water for their daily used. Those factors might elevate infection rate in this community. Similar types or results were published by other researchers (Kharel 2000, Adhakari et al. 2004, Williams-Blangero et al. 1998) in different parts of Nepal. Highest rate of infection found in female lead by their role in house and farmland. Females are often considered as a cheap agriculture labor. Discrimination between male and female in the poor countries made them unaware about these helminthes and epidemiology (Rousham 1994) had significant impact on helminth infection in women.

Majority of population of age between 0-9 year were always in parents' supervision and either go to school or stay home. They did not allow playing in the contaminated field. Conversely, the older people either retired from work or did not have a job and worked as a labour so they had more chance to contaminate with intestinal parasites.

Hookworm has more chance to infect human then other parasites because an infectious larva of hookworm can transmit through skin and finally move to the intestine of host (Brooker et al. 2004). It also transmits through oral route like other helminthic parasites. Similar results were published by other researcher (Khetan 1980, Bangs et al. 1996) also found the similar type of result. The study population have more single infection however double and triple infection also found. Hookworm was dominant parasites that transmit by walking bare foot that makes higher proportion of single infection. These people used river water and pond water for daily purposed and these water sources during rainy season have more chance of contamination. That could lead other infections along hookworm infection. Fugita et al. (1993) conducted a survey in five rural communities at Paraguya and observed similar result.

This study indicated that helminthic infection was still large in the poor, like studied community. Lack of toilet in the house, lack of knowledge, use of contaminated river and pond water and walking bare foot made bad things worst. These people were unaware of epidemiology of helminths and consequence of them. Female population are more exposed to the parasites due to their nature of work. More aged people were suffering from disease due to lack of immune system and walking bare foot. More study is required to identify actual casualty as well as magnitude of infection in the people. 


\section{Acknowledgements}

I wish to sincere thanks to community people who provide their faecal specimens and Gaindakot VDC for providing such valuable information regarding Kumal population. I also thank Central Department of Zoology, Tribhuvan University for providing their fully equipped laboratory, chemicals to us for observation.

\section{References}

Adhikari, N., R. Bomjan, D.B. Khatri, D.R. Joshi, I. Dhakal and B. Lekhak, 2004. Intestinal helminthic infections among school children in Kathmandu valley. Journal of Nepal Health Research Council 5 (1): 17-21.

Bangs, M.J., E.M. Purnomo and R.L. Anthony 1996. Intestinal parasites of human in a highland community of Ivian Jaya, Indonesia. Annals of Tropical Medicine and Parasitology 90(1): 49-53.

Bethony, J., S. Brooker, M. Alboico, S.M. Geirger, A. Loukas, D. Diemart and P.J. Hotez. 2006. Soil transmitted helminth infections: Ascariasis, trichuriasis, and hookworm. Lancet 367:1521-1532.

Biggs, E.M. and G.R. Watmough. 2011. A community level assessment of factors affecting livelihoods in Nawalparasi district, Nepal. Journal of International Development 24: 255-263.

Brooker, S., J. Bethony, and P.J. Hotez. 2004. Human hookworm infection in the 21 st century. Advance Parasitology 58: 197-288.

Chaudhary, N.K. 2001. Knowledge system on the use of indigenous medicinal plants in Tharu community: Anthropological case study of Bachhauli VDC of Chitwan District, Narayani Zone. Master's thesis. Department of Sociology and Anthropology, Tribhuvan University, Kirtipur, Nepal.

Dryden, M.W., P.A. Payne, R.K. Ridley and V.E. Smith. 2006. Compendium on continuing education for the practicing veterinarian. Veterinary Learning Systems. 28: 3-13.
Friedman, J.F., H.K. Kanzaria, L.P. Acosta, G.C. Langdon, D.L. Manalo, H. Wu, R.M. Olveda, S.T. McGarvey and J.D. Kurtis. 2005. Relationship between Schistosoma japonicum and nutritional stuatus among children and young adults in Leyte, the Philippines. American Journal of Tropical Medicine and Hygiene 72(5): 527-33.

Fugita, O., M. Ohnishi, , V. Diaz, L. Martinez. and L. Kamiya, 1993. Epidemiological investigation for intestinal parasitic infection in children in rural communities in Paraguey. Japanese Journal of Parasitology 42(5): 409-414.

Gordon, C.A., G.J. Darren, G.N. Geoffrey. and M.P. Donald. 2011. DNA amplification approaches for the diagnosis of key parasitic helminth infections of humans. Molecular and Cellular Probes 25: 143152.

Kharel, D. 2000. Prevalence of intestinal helminth parasitic infection in general and hookworm in particular on Bhutanese refugees settled in Jhapa district of Nepal. M.Sc. thesis. Central Department of Zoology, Tribhuvan University, Kirtipur, Nepal.

Khetan, R. P. 1980. Incidence of parasitic infestation in Narayani zone. Journal of Nepal Medical Association 18: $29-31$.

Liang, S. and R.C. Spear. 2008. Model-based insights into multi-host transmission and control of Schistosomiasis. PLoS Medicine 5: 14-15.

Rousham, E.K. 1994. Perceptions and treatment of intestinal worms in rural Bangladesh. Journal of Social Science Medicine 39 (8): 1063-1068.

Sharma, B.P. 1965. Roundworms and their infestation. Journal of Nepal Medical Association. 3 (2).

Thompson, R.C., J.A. Reynoldson, S.C. Garrow, J.S. McCarthy. and J.M. Behnke. 2001. Towards the eradication of hookworm in an isolated Australian community. Lancet 357: 770-771.

Thompson, R.C.A. and J.V. Conlan. 2011. Emerging issues and parasite zoonoses in the SE Asian and Australasian region. Veterinary parasitology 181: 69-73. 